\title{
Heat transfer during pulsating liquid jet impingement onto a vertical wall
}

\author{
J. Wassenberg ${ }^{1}$ (I) $\cdot$ P. Stephan ${ }^{1} \cdot$ T. Gambaryan-Roisman ${ }^{1}$
}

Received: 2 July 2020 / Accepted: 21 September 2020 / Published online: 10 October 2020

(C) The Author(s) 2020

\begin{abstract}
Liquid jet impingement is used for cooling and cleaning in various industrial branches. The advantages of jet impingement include high heat and mass transport rates in the vicinity of the impingement point. Pulsating liquid jets impinging on horizontal substrates with a pulsation frequency around $100 \mathrm{~Hz}$ have been shown to increase the cooling efficiency in comparison to jets with continuous mass flow rates. The influence of jet pulsation on cooling efficiency for impingement of horizontal jets onto vertical walls has not yet been investigated. In the case of a vertical heated wall, gravity contributes to the liquid flow pattern. In particular, if the time span between two pulses is sufficiently long, the liquid drainage from the region above the impingement point can contribute to heat transport without increasing the average flow rate of the cooling medium. In this work, the influence of pulsations on heat transfer during impingement of a horizontal liquid jet onto a vertical wall is investigated experimentally for the pulsation frequency range $1-5 \mathrm{~Hz}$. The results regarding increase of heat transfer efficiency are related to flow patterns developing by impingement of successive pulses, as well as to the liquid splattering.
\end{abstract}

\section{Nomenclature}

$\mathrm{A}_{\mathrm{H}}$

$\mathrm{c}$

$\mathrm{d}_{\mathrm{N}}$

$\mathrm{DC}$

f $\quad$ Pulsation frequency, $\mathrm{Hz}$

fr $\quad$ Frame rate (high speed camera), $\mathrm{Hz}$

h Heat transfer coefficient, $\mathrm{W} \mathrm{m}^{2} \mathrm{~K}^{-1}$

L Nozzle distance, distance between nozzle and target, $\mathrm{m}$

$\dot{\mathrm{M}}, \dot{\mathrm{M}}_{\mathrm{r}}, \dot{\mathrm{M}}_{\mathrm{s}} \quad$ Mass flow through nozzle, remaining mass flow, splattered mass flow, $\mathrm{kg} \mathrm{s}^{-1}$

Q $\quad$ Total heat flow introduced, W

$\mathrm{R} \quad$ Radius of cylindrical heater, $\mathrm{m}$

$\mathrm{r} \quad$ Radial coordinate measured from point of impingement, $\mathrm{m}$

Electronic supplementary material The online version of this article (https://doi.org/10.1007/s00231-020-02973-z) contains supplementary material, which is available to authorized users.

J. Wassenberg

wassenberg@ttd.tu-darmstadt.de

Institute for Technical Thermodynamics, Technische Universität Darmstadt, Darmstadt, Germany $\mathrm{r}_{\mathrm{s}}$

$\mathrm{T}_{\mathrm{w}}, \mathrm{T}_{1}$

$t, t_{s}$

$\mathrm{u}_{\mathrm{jet}}$

$\mathrm{X}, \mathrm{Y}$

$\mu$

$v$

$\xi$

$\rho$

$\tau, \tau_{\text {on }}, \tau_{\text {off }}$

$\operatorname{Re}$

$\mathrm{Sr}$

St

$\mathrm{St}_{\varphi}$

St

Radial position of splattering, at which droplets leave the wall flow, $r_{s}=5.71 d_{N} T_{w}, T_{1}$

Measured wall temperature, liquid temperature (water) at nozzle inlet, $\mathrm{K}$

time, shutter time (high speed camera), $\mathrm{s}$

Free liquid jet velocity $\mathrm{m} \mathrm{s}^{-1}$

Extent of the radial flow zone in the horizontal and vertical direction measured from the point of impingement $\mathrm{m}$

Dynamic viscosity (water), $\mathrm{kg} \mathrm{m}^{-1} \mathrm{~s}^{-1}$

Kinematic viscosity (water), $\mathrm{m}^{2} s^{-1}$

Splattered mass fraction,

$\xi=\dot{\mathrm{M}}_{\mathrm{s}} / \dot{\mathrm{M}}=1-\dot{\mathrm{M}}_{\mathrm{r}} / \dot{\mathrm{M}}$

Density (water), $\mathrm{kg} \mathrm{m}^{-3}$

Duration of one period, nozzle operating time, nozzle pause time, $\mathrm{s}$

Reynolds number of a pulsating liquid jet,

$\operatorname{Re}=4 \dot{\mathrm{M}} \cdot / \pi \mathrm{d}_{\mathrm{N}} \mu \mathrm{DC}$

Strouhal number of a pulsating liquid jet, $\mathrm{Sr}=\mathrm{fd} \mathrm{d}_{\mathrm{N}} / \mathrm{u}_{\text {jet }}$

Stanton number of a pulsating liquid jet, $\mathrm{St}=\frac{\mathrm{A}_{\mathrm{H}}(\mathrm{r}) \mathrm{h}}{\mathrm{M} \cdot \mathrm{c}}$

Mean Stanton number in direction of

$\varphi, \mathrm{St}_{\varphi}=\frac{\mathrm{Q}}{\left|\mathrm{T}_{\mathrm{w}}-\mathrm{T}_{1}\right| \mathrm{M} \cdot \mathrm{c}}$

Mean Stanton number

$\mathrm{St}=\left(\mathrm{St}_{0}+2 \mathrm{St}_{\pi / 2}+\mathrm{St}_{\pi}\right) / 4$ 


\section{Introduction}

Liquid jet impingement is used in industry when surfaces must be cooled or cleaned, since this process is characterized by high heat or mass transport rates in the vicinity of the impingement point. Liquid jet impingement heat transfer was extensively studied during the 1990's experimentally and theoretically [1-4]. Liu et al. [2, 3] developed two different models describing the heat transfer depending on the liquid Prandtl number being above or below unity. The authors divide the wall flow driven by vertical impingement of a laminar jet onto a horizontal heated wall into several sections: For $\operatorname{Pr}>1$ these sections are the stagnation zone, the boundary layer development zone, lasting until the viscous boundary layer reaches the free surface, the similarity region, in which the temperature distribution across the film thickness is selfsimilar, followed by the transition to turbulence and eventually to the fully turbulent flow. The measurements of Stevens and Webb [5] indicated that the former division is also valid for a vertical set up. Highest heat transfer rates are found in the region of the stagnation zone and the region of thermal boundary layer development.

One of the important factors limiting the heat transfer rate during jet impingement is the splattering of liquid from the wall. Splattering has been typically observed for turbulent liquid jets and high nozzle-to-target distances (nozzle distances). Based on the velocity measurement of the splattered droplets, it has been assumed that the splattering takes place downstream the radial position (also known as the radius of splattering) $r_{s}=5.71 d_{N}[6]$, where $d_{N}$ denotes the nozzle diameter. Splattering is often quantified by the splattered mass fraction $\xi$, which is the ratio between the mass flow rates of the splattered liquid and impinging liquid [7-12]. Correlations describing the splattered mass fraction can be found in [9] for coherent jets $\left(\mathrm{L} / \mathrm{d}_{\mathrm{N}}<50\right)$ and pipe nozzles, as well as in [11] for disintegrated jets $\left(L / d_{N} \geq 250\right)$. Both correlations state that $\xi$ increases with the jet Weber number.

Several methods for heat transfer enhancement have been suggested, including artificial wall roughness [13], gas injection from capillary tubes, positioned at the jet centerline, into a liquid jet [14], and pulsation. Zumbrunnen and Aziz [15] investigated the influence of pulsation created by a cutter blade on heat transfer during impingement of water jets onto a horizontal wall. Using pulsation with frequencies up to $140 \mathrm{~Hz}$ lead to an enhancement of the heat transfer in the stagnation zone of up to $100 \%$ [15]. The enhancement, in this case, is related to a renewal of the thermal boundary layer, which was shown to become dominant for Strouhal number $\mathrm{Sr} \geq 0.26$ $[15,16]$. The Strouhal number is defined by the pulsation frequency, the characteristic length and speed of the jet:

$\mathrm{Sr}=\mathrm{fd}_{\mathrm{N}} / \mathrm{u}_{\mathrm{jet}}$
Besides the pulses created by a cutter blade (rectangular pulse form), other pulse forms, such as sinusoidal, have been applied in an attempt to enhance the heat transport. However, they did not lead to similar enhancement factors or even to decreasing the heat transfer coefficient [17]. Further increase of the pulsation frequency results in a transformation of the intermittent jet into a droplet train and also does not lead to a further increase of the heat transfer rate $[18,19]$. Ongoing research on pulsating impinging jets is focused on submerged gas jets. For instance, Middelberg and Herwig [20] investigated the heat transfer of pulsating air jets and find an enhancement in heat transfer of up to $60 \%$ in the stagnation flow area in comparison to the continuous jet. To the knowledge of the authors, the effect of pulsation on heat transfer by impingement of horizontal liquid jets on vertical walls has not been investigated yet.

The flow pattern resulting from the impact of a horizontal jet onto a vertical wall is schematically represented in Fig. 1. The impingement of a circular liquid jet onto a vertical wall is - as for the horizontal wall - accompanied by the formation of stagnation flow and the development of a thin liquid film, or the radial flow zone (RFZ, zone 1 in Fig. 1), in which the velocity is dominated by its radial component [21]. The radial flow zone is bounded by a hydraulic jump. However, in the case of a vertical wall, the latter is not circular as in the case of a normal impingement onto horizontal surfaces, but has an arc shape [11], as illustrated in Fig. 1. Since the velocity, and thus the heat and mass transfer rates, are reduced in the region of the hydraulic jump, the extent of the RFZ in the horizontal and vertical directions denoted by $\mathrm{X}$ and $\mathrm{Y}$, respectively (see Fig. 1b), are of particular interest. Outside the hydraulic jump, a circumferential flow (or rope flow, 2) is formed, which merges with the RFZ considerably below the POI forming a falling film (3). For low nozzle distances, splattering is not significant, and the extent of RFZ in the horizontal direction can be predicted from the model equation suggested by Wilson [22]:

$X=0.276\left(\frac{\dot{\mathrm{M}}^{3}}{\mu \gamma \rho}\right)^{\frac{1}{4}}$

Equation (2) with the mass flow rate $\dot{M}$, the dynamic viscosity $\mu$, the surface tension $\gamma$, and the liquid density $\rho$ states that $\mathrm{X}$ only depends on the mass flow rate for the given liquid. Higher nozzle distances lead to more developed surface disturbances of the impinging jet, which generally causes splattering from the wall flow $[8,9,11]$. Since splattering leads to a reduction of the wall flow momentum, the extent of the RFZ in both directions is also 
Fig. 1 Schematic of the liquid flow pattern for continuous jet impingement in side view (a) and top view (b) with the radial flow zone (1), the rope flow (2), and the falling film zone (3)

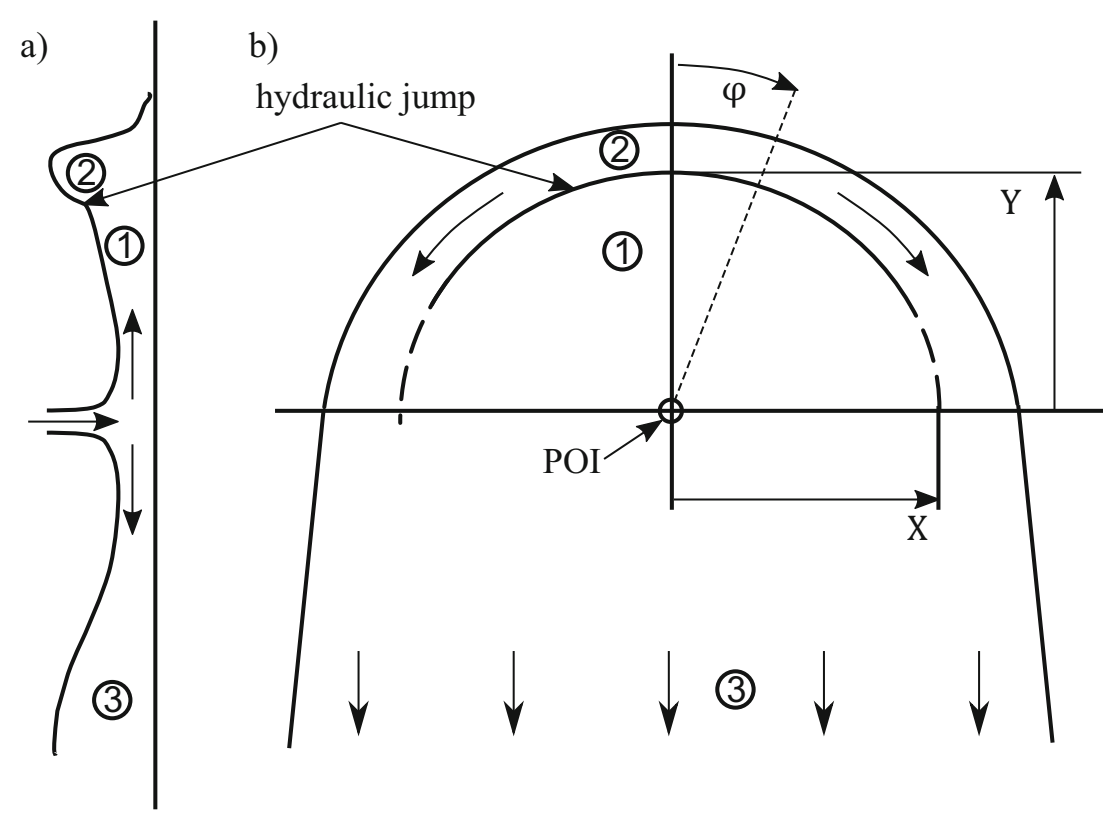

2 Experimental method

reduced. In this case, the model developed in [11], in which the splattering is accounted for, provides a more accurate prediction of the RFZ extent.

The impingement of a pulsating jet (consisting of successive jet sections) leads to development of complex periodic wall flow patterns. The development of flow patterns between the impingements of two successive pulses (jet sections) typically can be subdivided into several phases: (i) the spreading phase directly after impingement, eventually leading into (ii) the quasi-steady phase, which lasts until the end of the jet section impingement phase. Phase (ii) exhibits the same flow pattern, as would result from continuous jet impingement and is characterized by a constant mass of water above the point of impingement (POI). After the jet is turned off (intermission of the impingement) phase (iii), the drainage of the wall film starts. It is expected that the drainage of the liquid stored in the rope above the impingement point contributes to convective heat transport and cooling of the heated wall without ongoing inflow of cooling liquid, and thus, could lead to improvement of resource efficiency of the jet impingement cooling process.

In the present work, the heat transfer between a horizontally impinging pulsating liquid jet and a vertical wall is investigated to discover if or to what extent jet pulsation leads to heat transfer enhancement. The range of jet impingement parameters and the range of pulsation parameters have been chosen in such a way that the duration of the spreading phase and the drainage phase are comparable with the duration of the impingement pulse. Experiments were performed at jet Reynolds numbers $\mathrm{Re}=20700-59000$ and pulsation frequencies $\mathrm{f}=1$ $-5 \mathrm{~Hz}$ with a pipe nozzle $\left(\mathrm{d}_{\mathrm{N}}=4 \mathrm{~mm}\right)$, and nozzle-to-wall distances in the range from 3 to 167 nozzle diameters.

\subsection{Experimental setup}

The main part of the test setup used in this work is the open water circuit pictured in Fig. 2a, which has been also used in [11], where a detailed description can be found. During the measurement water is pumped from the tank (1) by a multistage centrifugal pump (2, IN-VB 2-140, Speck) passing through the Coriolis mass flow meter (TME 5, Heinrichs Messtechnik $\mathrm{GmbH})$. The water temperature is kept at $20 \pm$ $1{ }^{\circ} \mathrm{C}$ using a counter flow heat exchanger and a bath thermostat (not depicted). The sectional valves (3, EV210B, Danfoss) are used to create the pulsation by either directing water to the tank or to the nozzle (4), where the liquid jet is formed. Both streams exhibit equal flow resistances. This leads to an intermittent pulsation form with an almost rectangular function of the nozzle pressure. The jet Reynolds number is then defined as follows:

$\operatorname{Re}=\frac{4 \dot{M}}{\pi d_{N} \mu \mathrm{DC}}$

In Eq. (3), DC is the duty cycle of the pulsation, which indicates the ratio of the mass flow rate through the nozzle to the total mass flow before the valves, $\dot{M}$ the time-averaged mass flow rate through the nozzle, and $\mu$ the dynamic viscosity of water. On the one hand, with this definition of Re the liquid jets with different pulsation duty cycle, but with equal velocity at nozzle exit have equal Reynolds numbers. On the other hand, jets with equal average mass flow rates and equal nozzle diameters do not necessarily have the same Reynolds 
Fig. 2 a Schematic of the test stand used in this work: (1) tank, (2) centrifugal pump, (3) sectional valves, (4) nozzle, (5) wall with integrated heater, (6) \& (7) collecting tubs, (8) sampling position, and (9) wet cell. b Drawing of heater and detailed cross section at a thermocouple position
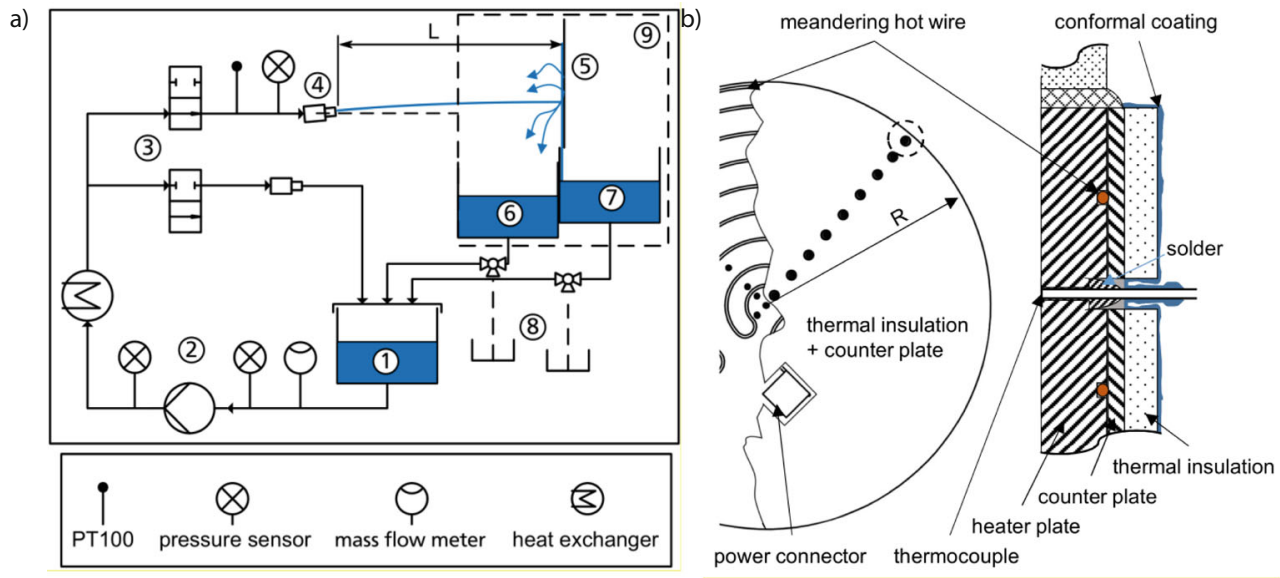

number. Anticipating that phase (ii) will be reached, jets with the same Reynolds number are able to wet approximately the same area.

In the wet cell (9), after passing the nozzle distance $\mathrm{L}$, the jet impinges on the center of a plate, which is heated by the meandering wire heater (5, Fig. 2b). After impingement a part of liquid with the mass flow rate $\dot{M}_{\mathrm{s}}$ is splattered, and the rest of the liquid with the mass flow rate $\dot{M}_{r}$ remains on the wall and cools the heater. Both mass flows are collected by separate tubs $(6 \& 7)$ and can be withdrawn from the circuit at the sampling point (8) into two separate containers. The nozzle is placed on a sled to be able to vary the distance L. In order to guarantee a horizontal impact, the nozzle's orientation is slightly deviating from horizontal.

\subsection{Heat transfer measurement}

$\backslash$ kern3ptThe heater plate is manufactured from nickel and has a cylindrical shape with a thickness of $8 \mathrm{~mm}$ and a radius of $\mathrm{R}=67.5 \mathrm{~mm}$ according to Fig. $2 \mathrm{~b}$. It is glued into a polycarbonate frame on surface level. The meandering wire on the back side is connected to a $1.5 \mathrm{~kW}$ power supply (Delta Electronica 1500) and countered by a $2 \mathrm{~mm}$ thick aluminum plate to ensure a thermal contact. Additional thermal (Isoplan ${ }^{\circledR} 1000,6 \mathrm{~mm}$ ) and electric insulation is applied. Therefore, more than $97 \%$ of the introduced heat is conducted to the surface of the plate. Thermocouples were soldered in at surface level along the radial coordinate $(r=0,4,8,16,24$, $32,40,48,56,63 \mathrm{~mm}$ ) from the POI and allow the measurement of the wall temperature $T_{w}(r)$ with a sampling rate of $60 \mathrm{~Hz}$. The heater surface was countered with an aluminum sheet and heated to $300^{\circ} \mathrm{C}$. Solder was filled into holes before the thermocouples were inserted and fixed. After cooling the aluminum was removed and the heater surface was carefully sanded. The heater can be rotated around its axis to allow measurements along different directions from the POI. The water temperature at the nozzle inlet $T_{1}$ is measured as well. Each experiment was carried out for $30 \mathrm{~s}$ after reaching a stationary state, which was indicated when the electric resistance of the meandering wire became stationary. The measurement data was gathered using LabVIEW® and then processed in Matlab®. The data was cut to fit a whole number of periods, e.g. 30 for $\mathrm{f}=1 \mathrm{~Hz}$. For each parametric setting 2-3 experiments were carried out on different days. Presented time-averaged temperatures in section 3 are averages of the different mean temperatures resulting from these experiments, while the error bars display maximum deviation from this mean. The wall temperatures can be used to characterize the heat transfer.

For equal Reynolds numbers defined in Eq. (3), the mass flow rate and thereby the heat transfer rate, can differ significantly. In order to quantify the heat transfer efficiency at a radial distance $r$ from POI, we introduce a modified local Stanton number [Eq. (4)]. This parameter can be interpreted as a relation between the heat transferred from the wall to the fluid within a circular region with the center at the POI and the radius $\mathrm{r}, \dot{\mathrm{Q}}_{1 \mathrm{D}}(\mathrm{r})=\dot{\mathrm{Q}} \cdot(\mathrm{r} / \mathrm{R})^{2}$, to the maximum heat $\dot{\mathrm{Q}}_{\max }$ that could be transferred, if the water temperature at the position $r$ was uniform and equal to the wall temperature:

$$
\begin{aligned}
\mathrm{St} & =\frac{\mathrm{A}_{\mathrm{H}}(\mathrm{r}) \cdot \mathrm{h} \cdot\left(\mathrm{T}_{\mathrm{w}}(\mathrm{r})-\mathrm{T}_{1}\right)}{\mathrm{M} \cdot \mathrm{c} \cdot\left(\mathrm{T}_{\mathrm{w}}(\mathrm{r})-\mathrm{T}_{1}\right)} \\
& =\frac{\mathrm{Q} \cdot(\mathrm{r} / \mathrm{R})^{2}}{\mathrm{M} \cdot \mathrm{c} \cdot\left(\mathrm{T}_{\mathrm{w}}(\mathrm{r})-\mathrm{T}_{1}\right)}=\frac{\dot{\mathrm{Q}}_{\mathrm{DD}}(\mathrm{r})}{\dot{\mathrm{Q}}_{\max }(\mathrm{r})}
\end{aligned}
$$

In Eq. (4) $\mathrm{h}$ denotes the heat transfer coefficient, $A_{H}$ a circular part of the heater surface, and $c$ the specific heat capacity. The heat flow $\dot{Q}_{1 D}(r)=Q \cdot(r / R)^{2}$ is evaluated under an assumption that radial heat conduction within the heater plate is negligible. The mean modified Stanton number $\overline{\mathrm{St}}$ is evaluated by averaging the Stanton numbers $\overline{\mathrm{St}}_{\varphi}$ determined 
from temperature measurements at different radial positions as shown in Fig. $2 \mathrm{~b}$ along the directions above, sideways (twice), and below the POI:

$\overline{\mathrm{St}}_{\varphi}=\frac{\dot{\mathrm{Q}}}{\left(\overline{\mathrm{T}}_{\mathrm{w}}-\mathrm{T}_{1}\right) \cdot \dot{\mathrm{M}} \cdot \mathrm{c}}$

$\overline{\mathrm{T}}_{\mathrm{w}}=\frac{2 \int_{0}^{\mathrm{R}} \mathrm{rT}_{\mathrm{w}} \mathrm{dr}}{\mathrm{R}^{2}}$

The spatial mean wall temperature $\overline{\mathrm{T}}_{\mathrm{W}}$ in Eq. (5) is calculated using Eq. (6), with the temporal mean temperatures and a cubic spline interpolation with zero slope at $r=0$ and $r=R$. The error bars shown in Figs. 8, 9 and $11 \mathrm{~b}$ are based on the uncertainty of the Stanton number, taking into account uncertainties of mass flow rate $(0.2 \%)$, temperatures $( \pm 0.2 \mathrm{~K})$ and heat flow $(3,3 \%)$ using error propagation.

\subsection{Flow visualisation}

In order to provide additional information about the wall-flow patterns governing the heat transport, high speed imaging was used. In a separate experiment the heater was exchanged by a transparent wall made of Plexiglas. The high speed camera (MotionBlitz EoSens Cube 7, Mikrotron $\mathrm{GmbH}$ ) was mounted behind the transparent wall and was enlightened from the side of the nozzle. The images were taken with a frame rate $\mathrm{fr}=1 \mathrm{kHz}$ and a shutter time $\mathrm{t}_{\mathrm{s}}=10 \mu \mathrm{s}$. The distance in pixels have been converted to millimeters using a reference image for the set camera position, giving $0.289 \mathrm{~mm} / \mathrm{Pi}$. Due to differences in the wetting properties of the materials, deviation between both experiments are possible. As the contact line, which is sensitive to wetting, is located outside the heated region on the polycarbonate, the deviations are negligible and the observed flow patterns are not affected.

\section{Results and discussion}

Before the heat transfer between wall and water is discussed, the developed flow patterns are described in detail along two examples. Figure 3 a shows a set of images displaying the flow patterns at different time instants $\mathrm{t}$ after the jet section impingement for $\mathrm{Re}=31000$, nozzle distance $\mathrm{L} / \mathrm{d}_{\mathrm{N}}=3$, pulsation frequency $\mathrm{f}=1 \mathrm{~Hz}$ and duty cycle of $50 \%$. In order to revisit Fig. 3 in section 3.1, the heater size is marked by the bright area. It can be seen that during phase (i) the spreading wall flow reaches the border of the heater at $\mathrm{t}=34 \mathrm{~ms}$ and reached its maximum extent above the POI at $t=60 \mathrm{~ms}$. At this point no hydraulic jump is visible and no rope is yet formed. As the gravity forces the water downward, a ridge is formed at the top of the RFZ, which is carried by the momentum of the incoming liquid. The ridge thickens and moves slightly downwards under the action of the gravity force, and the vertical distance between the ridge and the POI decreases. The thickening process evolves until water eventually flows along the circumference and the rope flow is formed. At $\mathrm{t}=150 \mathrm{~ms}$ the rope is partially evolved. The quasi-steady state is reached approximately $300 \mathrm{~ms}$ after impingement of the jet front and phase (ii) begins. This process has already been described in [23]. In the present case, the rope is so thick that the Rayleigh-Taylor instability is developed, leading to the formation of a bulge, which then drips form the rope (arrow at $\mathrm{t}=540 \mathrm{~ms}$ ). For continuous jet impingement the process repeats and causes frequent dripping of the liquid. At $\mathrm{t}=$ $500 \mathrm{~ms}$ the jet is turned off, but the water impinging at that point still spreads radially outwards until $t=540 \mathrm{~ms}$. Then the wall film, which is left after the jet was turned off, begins to drain and phase (iii) starts. The liquid stored within the rope at the end of phase (ii), drains in form of a prominent wave. The wave passes the POI about $650 \mathrm{~ms}$ after the jet front impingement, leaving behind a thin, slowly flowing film. However, if the duration of the jet section (pulse) impingement phase, which depends on the pulsation frequency, is shorter than the time needed to reach the quasi-steady flow pattern, the phase (ii) will not be reached. Further, if the duration of intermission is sufficiently short, the draining wave does not pass the POI until the impingement of the next pulse. This implicates a collision between the spreading wall flow and the draining wave of the previous pulse. In Fig. $3 \mathrm{~b}$ the flow patterns for the jet impingement at the pulsation frequency of $\mathrm{f}=$ $5 \mathrm{~Hz}$ are presented. All other parameters are maintained the same as in Fig. 3a. It can be observed that the jet impinges below the draining wave, which was formed in phase (iii) of the previous pulse. During phase (i), at $\mathrm{t}=26 \mathrm{~ms}$ the spreading wall flow collides with the draining wave, which decelerates the spreading of the former considerably. At $t=53 \mathrm{~ms}-19 \mathrm{~ms}$ later than for $\mathrm{f}=1 \mathrm{~Hz}$ - the spreading wall flow reaches the edge of the heater. The maximum extent above the POI is reached at $\mathrm{t}=100 \mathrm{~ms}$, when the jet is turned off, and thus phase (ii) is not reached. The rope appears thinner. Draining starts at $\mathrm{t}=130 \mathrm{~ms}$ and the draining wave reaches the upper edge of the heater at $\mathrm{t}=175 \mathrm{~ms}$. For both image series of Fig. 3 , videos are provided in supplementary material 1 and 2 . There, the circles mark the thermocouple positions for the heater oriented in the upward position and the brighter region marks the extent of the heater.

\subsection{Heat transfer and flow patterns}

In the following, we first examine the phenomena governing heat transfer during pulsating jet impingement. Afterwards we contemplate the influence of pulsation on heat transfer efficiency in the frequency regime $\mathrm{f}=1-5 \mathrm{~Hz}$.

In Fig. 4, the measured time average temperature difference $\Delta \mathrm{T}$ between water at the nozzle inlet and the wall is plotted 
Fig. 3 Image series showing the wall-flow pattern for a duty cycle of $50 \%$ and frequencies of $\mathrm{a} f=$ $1 \mathrm{~Hz}$ and $\mathbf{b} 5 \mathrm{~Hz}$. The jet is turned off for time instants $\mathrm{t}>500 \mathrm{~ms}$ respectively $\mathrm{t}>100 \mathrm{~ms}$. Bright area marks extent of heater. $(\mathrm{Re}=$ $31000, \mathrm{~L} / \mathrm{d}_{\mathrm{N}}=3$ )
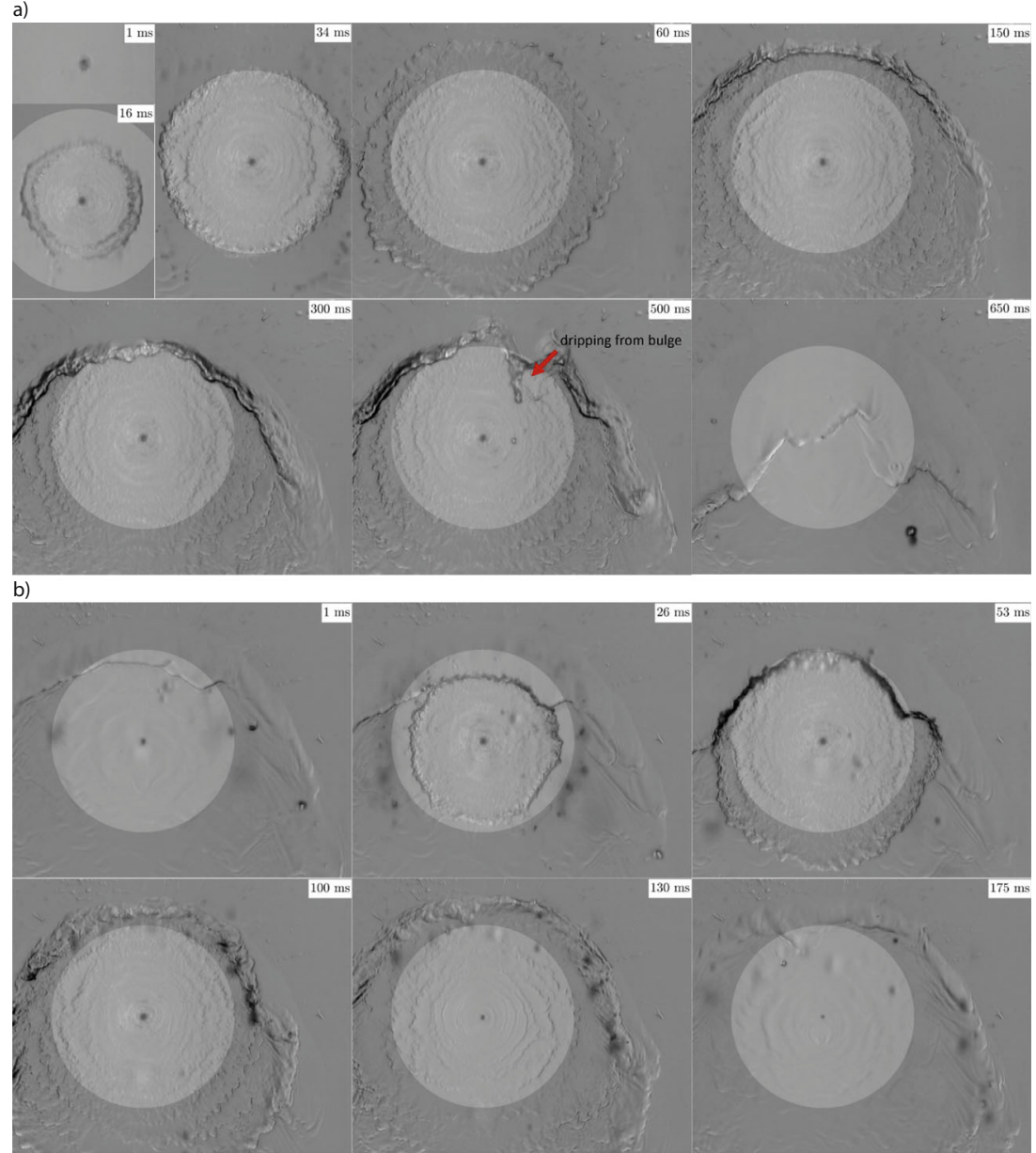

versus the distance from the POI for different pulsation frequencies. In the following, this temperature difference will be referred to as the wall temperature. The wall temperatures are measured above $(\uparrow)$ and below $(\downarrow)$ the POI, and the nozzle-to- target distance is $\mathrm{L} / \mathrm{d}_{\mathrm{N}}=3$. It can be seen that in case of the continuous jet $\Delta \mathrm{T}$ is independent of the orientation.

Since the time-averaged mass flow rate of the impinging cooling liquid is reduced by $50 \%$ for the pulsating jet, $\Delta \mathrm{T}$
Fig. 4 Mean temperature difference between heated wall and liquid at the nozzle inlet for different pulsation frequencies $(\mathrm{Hz})$ at the duty cycle $50 \%$, as well as for continuous jet $(\mathrm{DC}=$ $100 \%)$. The upwards directed arrow denotes the temperatures measured with thermocouples located above the POI, and vice versa. $\left(\operatorname{Re}=31000, \mathrm{~L} / \mathrm{d}_{\mathrm{N}}=3\right)$

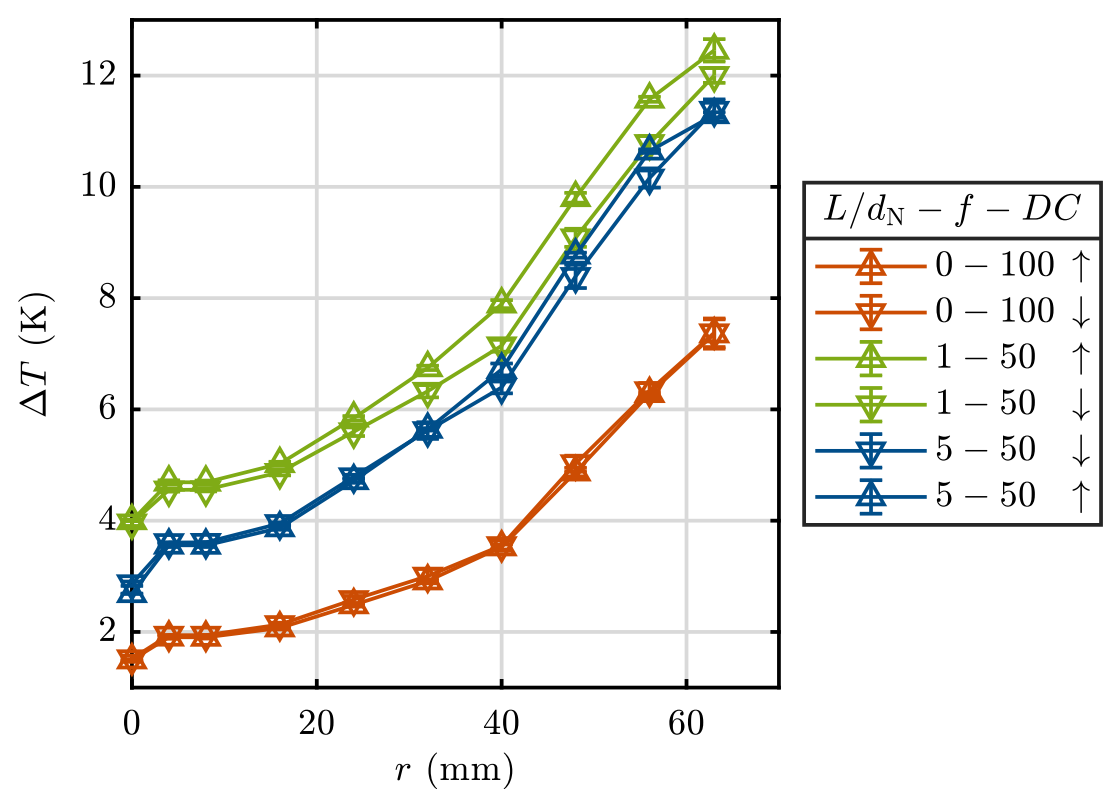


increases. The temperatures at different locations strongly depend on the pulsation frequency, and in contrast to the continuous jets, they are significantly different for the regions above and below the POI. For $\mathrm{f}=1 \mathrm{~Hz}$ the temperatures above are higher than below the POI. As was discussed in the context of the flow patterns presented in Fig. 3a, the former rope flows down the wall in a form of a wave, leaving behind a relatively thin and slow film. The regions above the POI are subject to this film for a longer period than regions below, which can be a reason of the lower heat transfer rate in this region. For $\mathrm{f}=$ $5 \mathrm{~Hz}$, the wall temperatures above and below the POI are identical for $\mathrm{r} \leq 36 \mathrm{~mm}$, while they are slightly higher above the POI than below in the region $\mathrm{r} \approx 40-56 \mathrm{~mm}$. This is the region in which the collision between the spreading wall flow and the draining wave of the previous pulse is seen. The retardation of the spreading wall flow could be responsible for the lower heat transfer in this region.

In Fig. 5 the time-averaged wall temperature at different thermocouple positions is shown for $\operatorname{Re}=59000$. The data are presented for $\mathrm{L} / \mathrm{d}_{\mathrm{N}}=3$ and for $\mathrm{L} / \mathrm{d}_{\mathrm{N}}=33$. It can be seen that the wall temperature distributions for continuous jet impingement $(\mathrm{f}=0 \mathrm{~Hz}$ ) differ for different nozzle distances. While the wall temperatures are identical at the POI, the difference becomes significant at $r=16 \mathrm{~mm}$. At $r=63 \mathrm{~mm}$, the wall temperature is about $2 \mathrm{~K}(\approx 50 \%)$ higher for the nozzle distance $\mathrm{L} / \mathrm{d}_{\mathrm{N}}=33$. As described in $[6-8,10,11]$, a higher nozzle distance leads to an increase in the splattered mass fraction of water, $\xi$. The splattered liquid is ejected from the wall flow, and thus does not contribute to heat transfer. According to [6], the splattering takes place at the radial distance $\mathrm{r}_{\mathrm{s}} \approx 5.71 \mathrm{~d}_{\mathrm{N}} \approx$ $23 \mathrm{~mm}$. This agrees well with the radial distance at which the temperatures measured for $L / d_{N}=3$ and for $L / d_{N}=33$ start to strongly deviate from each other. For discontinuous jet impingement, one case with $\mathrm{f}=2 \mathrm{~Hz}$ and another case with $\mathrm{f}=$
$5 \mathrm{~Hz}$ are shown, also in Fig. 5. For $\mathrm{f}=5 \mathrm{~Hz}$, other than in Fig. 4 , no difference between temperatures above and below POI is seen. The collision between spreading wall flow and draining wave takes place above and outside the heated region. Additionally, it can be seen that the wall temperatures are generally lower for $\mathrm{f}=5 \mathrm{~Hz}$ than for $\mathrm{f}=2 \mathrm{~Hz}$. The only exception is at $r=63 \mathrm{~mm}$ above the POI. Since the provided mass flow rate is equal, it can be already seen that the heat transfer efficiency is increased for $\mathrm{f}=5 \mathrm{~Hz}$. In Fig. 6, three other cases for $\mathrm{f}=2 \mathrm{~Hz}$ with different duty cycles are shown, while continuous jet impingement is kept for comparison. It can be seen that the wall temperatures are similar for both directions (above and below the POI) for $\mathrm{r} \leq 48 \mathrm{~mm}$.

Only for $r \geq 56 \mathrm{~mm}$ the temperatures below the POI are higher than above. In order to rationalize this behavior, consider the wall temperature versus time plot presented in Fig. 7a. The curves are smoothed with a third-order smoothing spline in order to improve the visibility. As the jet is turned on at the beginning of each period and the liquid impinges the hot surface, the surface is cooled initially rapidly, whereas the rate of temperature decreasing slows down with the time. When the jet is turned off, the heat transport rate reduces and the wall temperature increases. It can be seen that the curves depicting the wall temperature evolution at a distance of $40 \mathrm{~mm}$ from the POI above and below this point are close to each other. However, the difference of temperatures above and below the POI is significant at larger distances from POI. In Fig. $7 \mathrm{~b}$ a set of images is shown demonstrating the flow patterns at different time instants $t$ after the impingement of the jet front for the parameters of Fig. 7a. These images cover one full cycle between two successive jet pulses. The circles mark the thermocouple positions above the POI. It can be seen that the spreading wall flow reaches the heater edge at $\mathrm{t}=28 \mathrm{~ms}$ and its maximum spreading at $96 \mathrm{~ms}$ after impingement
Fig. 5 Mean temperature difference between heated wall and liquid at the nozzle inlet for different pulsation frequencies $(\mathrm{Hz})$ and duty cycles $(\%) .(\mathrm{Re}=$ $59000, \mathrm{~L} / \mathrm{d}_{\mathrm{N}}=3,33$ )

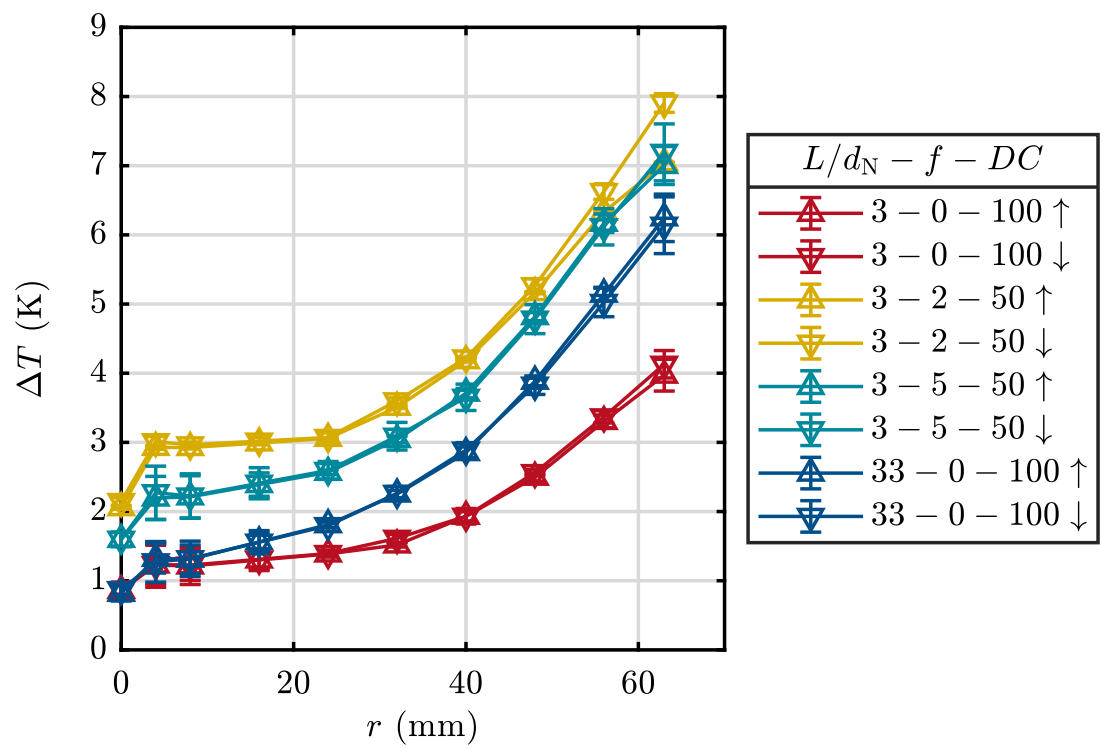


Fig. 6 Mean temperature difference between heated wall and liquid at the nozzle inlet for continuous and pulsating jet impingement. Pulsation with $\mathrm{f}=$ $2 \mathrm{~Hz}$ and different and duty cycles $(\%) .\left(\operatorname{Re}=59000, \mathrm{~L} / \mathrm{d}_{\mathrm{N}}=3\right)$

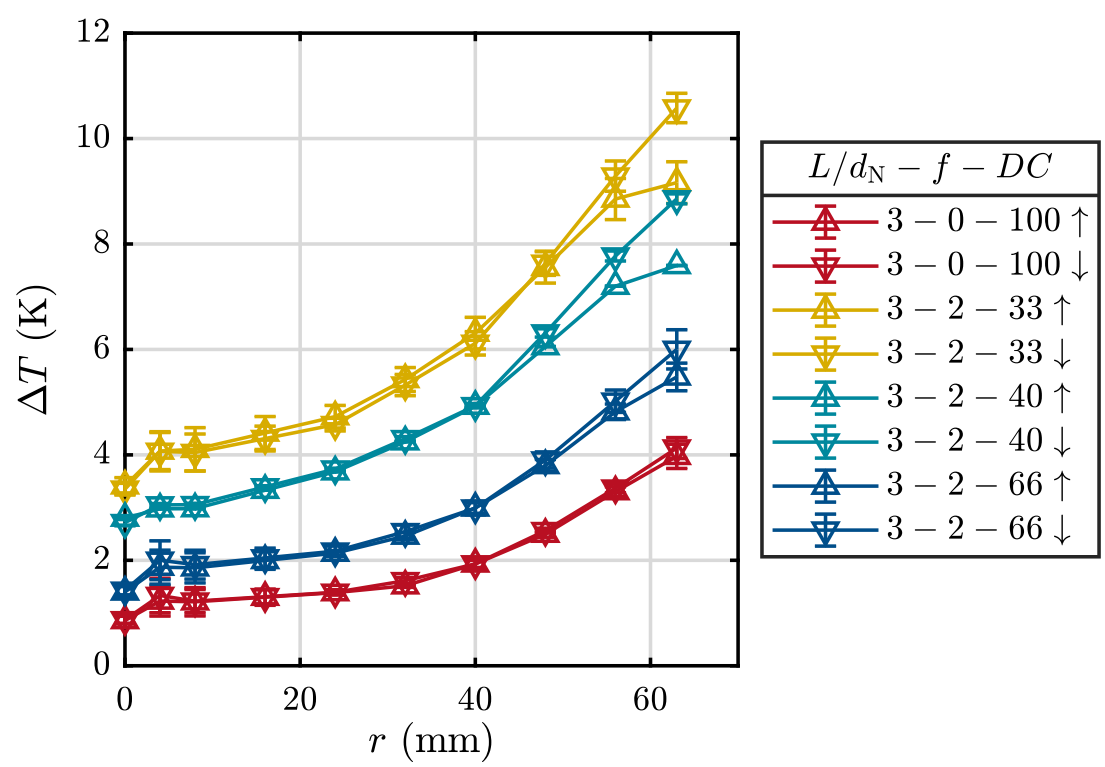

during phase (i). At $189 \mathrm{~ms}$ - shortly before the turn-off - a rope is formed, but phase (ii) is not reached, since a quasisteady pattern is not yet established at the instant of the jet turn-off. After the turn-off the liquid from the rope starts flowing down as a wave. This wave passes the thermocouples located at $63 \mathrm{~mm}$ and $56 \mathrm{~mm}$ above the POI at a time instant around $\mathrm{t}=314 \mathrm{~ms}$. At about this time, little dents are visible in the rising parts of the plots in Fig. 7a for data 56 and $63 \mathrm{~mm}$ above the POI (arrows). However, further downstream at $r=$
$40 \mathrm{~mm}$ and at all the position below no such dents are visible. We believe that the liquid at the hydraulic jump located above the heater is cool, since the thermal boundary layer stays thin within the RFZ. When the wave forms and begins to flow down the wall, it contributes considerably to the cooling of the wall. Since the wall temperature sharply increases with increasing $\mathrm{r}$ in this region, the temperatures within the boundary layer in the wave could get higher than the wall temperature downstream, so that the wall, starting from some radial
Fig. 7 a Temperature difference (smoothed) between heated wall and liquid at the nozzle inlet at three distances above $(\uparrow)$ and below $(\downarrow)$ the POI. b image series showing the wall-flow pattern and the corresponding thermocouple positions (colors code). Bright area marks extent of heater. $(\mathrm{Re}=$ $59000, \mathrm{f}=2 \mathrm{~Hz}, \mathrm{DC}=40 \%, \mathrm{~L} /$ $\mathrm{d}_{\mathrm{N}}=3$ ) a)

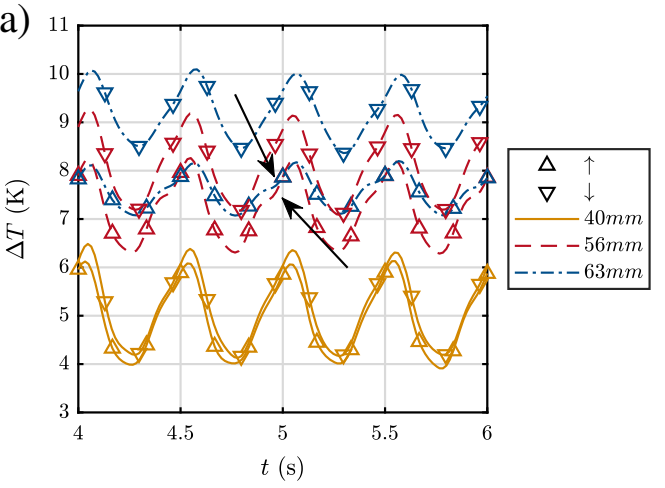

b)

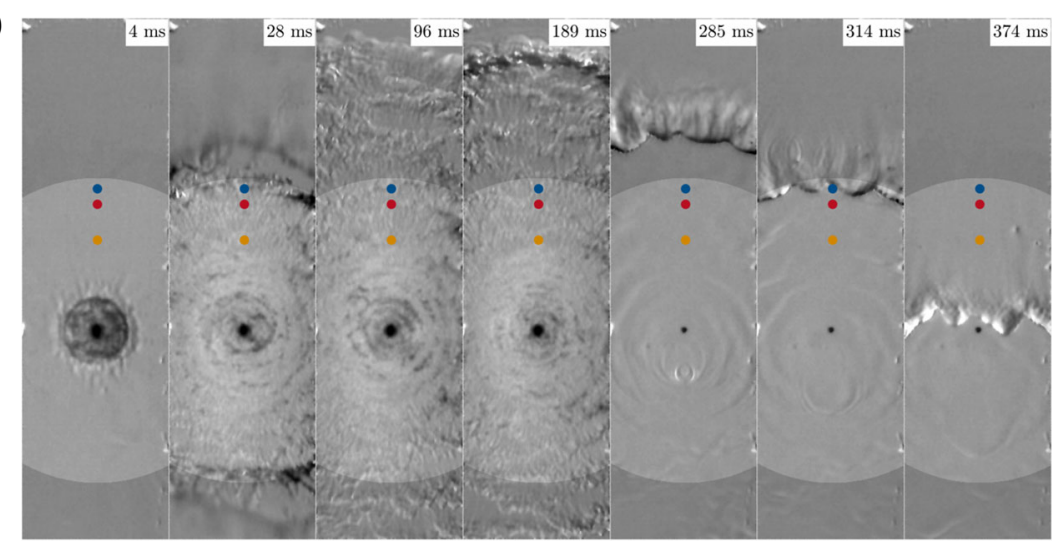


position, is not cooled by the wave flowing down. This effect can contribute to lower temperatures at the location $63 \mathrm{~mm}$ above the POI in comparison to the location $63 \mathrm{~mm}$ below the POI. It is noteworthy that the presented data for $\mathrm{f}=2 \mathrm{~Hz}$ in Fig. 6 are to some extent reversed to the data presented in Fig. 4 for $\mathrm{f}=1 \mathrm{~Hz}$. However, the time span between the passing of the POI by the draining wave and the impingement of the next pulse, in which the heater is basically not cooled above the POI is considerably different. While the time span takes the value of about $350 \mathrm{~ms}$ for $\mathrm{f}=1 \mathrm{~Hz}$, it takes the values of only about $120 \mathrm{~ms}$ for $2 \mathrm{~Hz}$ and $\mathrm{DC}=40 \%$.

It can be observed that, as expected, the decrease in duty cycle and respectively of the average mass flow rate leads to increasing the wall temperature. At the same time, also the difference between the wall temperatures at the outer thermocouple positions above and below increases with decreasing duty cycle. Since the amount of water impinging during each period reduces accordingly, the share of heat transferred during phase (iii) with respect to the total heat transferred increases. How this increase relates to heat transfer efficiency will be discussed along Fig. 8 using the Stanton number.

\subsection{Heat transfer efficiency}

In order to evaluate the heat transfer efficiency, the Stanton number introduced in Eq. (4) is plotted in Fig. 8 for selected data that has been presented in Figs. 5 and 6 . The Stanton number is low in the center, where the thermal boundary layer is thin, and increases monotonically for pulsating flows, while a plateau is reached for continuous flow at $r \approx 48 \mathrm{~mm}$. It can be seen that the Stanton numbers for all parameter sets at $\mathrm{L} / \mathrm{d}_{\mathrm{N}}=$ 3 are close to each other, but higher duty cycles lead to higher Stanton numbers in the range of $r=24$ to $48 \mathrm{~mm}$. For $r>$ $48 \mathrm{~mm}$, lower duty cycles lead to higher Stanton numbers.
Additionally, it can be seen that the difference between the Stanton numbers above and below the POI is highest for the lowest duty cycle. A possible explanation is the relative influence of the draining wave, which increases with lowering the duty cycle. Further, for a duty cycle of 33\%, the jet has been turned on $167 \mathrm{~ms}$ and the rope flow - meaning the circumferential velocity within the rope - is not fully developed, while a considerable ridge is formed already. In this case, in relation to the mass that impinges within one period, a larger amount of water is located above the heater and provides cooling in phase (iii). In other words, the longer turn-on time for the higher duty cycles does not lead to larger amounts of water stored above the heater, and the excess water does not contribute to cooling in phase (iii). The continuous impinging jet at $\mathrm{L} / \mathrm{d}_{\mathrm{N}}=33$ exhibits the lowest Stanton number for $\mathrm{r} \geq$ $24 \mathrm{~mm}$. This can be explained by a high splattered mass fraction for this parameter set $(\xi=0.5)$, which does not contribute to heat transport.

The average Stanton number $\overline{\text { St }}$ provides a means for comparing the heat transfer efficiency of cases within a large range of parameter sets. In Fig. 9, the data for several Reynolds numbers and nozzle distances are compared. Note that $\mathrm{Re}=$ 20700, DC $=100$ and $\mathrm{Re}=41700, \mathrm{DC}=50$ exhibit about equal mass flow rates. First, the results for $L / d_{N}=3$ will be discussed. Comparing only the results for $\mathrm{Re}=41700$, one can see that for a constant duty cycle, the Stanton number increases with increasing frequency, while for each frequency, the Stanton number increases with decreasing duty cycle. For the lowest duty cycle, $\mathrm{f}=2 \mathrm{~Hz}$ and $\mathrm{DC}=20 \%$, the highest enhancement of $26 \%$ is reached in comparison to the same Reynolds number and continuous flow. While the efficiency is increased, cooling itself is reduced due to the decrease in the average mass flow rate to $20 \%$ and the mean wall temperature is about $59 \%$ higher. When compared to the same mass flow
Fig. 8 Stanton number for $\mathrm{Re}=$ 59000 and different pulsation frequencies $(\mathrm{Hz})$, and duty cycles $(\%) .\left(\mathrm{L} / \mathrm{d}_{\mathrm{N}}=3\right.$ and 33$)$

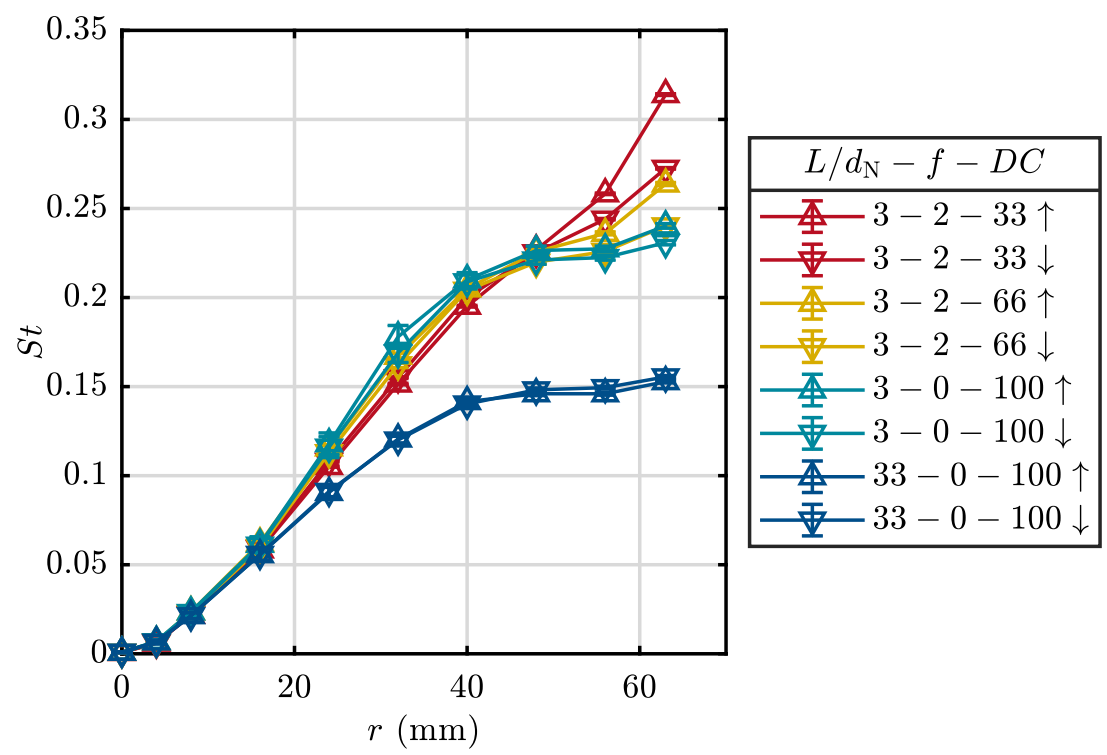


Fig. 9 Mean Stanton number for $\mathrm{Re}=41,700$ as well as further Reynolds numbers, for different pulsation frequencies $(\mathrm{Hz})$ and duty cycles $(\%)$. $\left(\mathrm{L} / \mathrm{d}_{\mathrm{N}}=3,33\right.$ and 167)

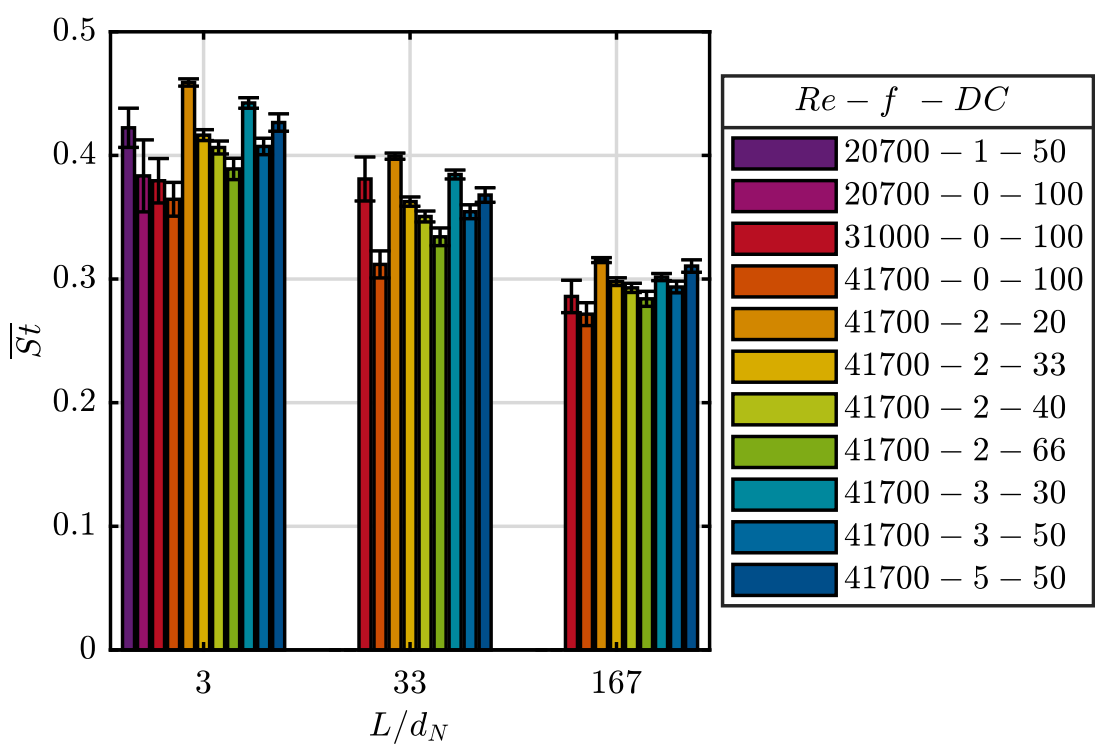

rate, e.g. $\mathrm{Re}=41700, \mathrm{f}=5 \mathrm{~Hz}$ and $\mathrm{Re}=20700$ for the continuous flow, the enhancement is generally lower (about 12\%). A comparison between $\mathrm{f}=2 \mathrm{~Hz}$ and $\mathrm{DC}=20 \%$ and continuous flow is not possible, since a jet with $\mathrm{Re}=8300$ corresponding to an average mass flow rate of $1.6 \mathrm{~kg} / \mathrm{min}$ would not spread over the entire heater area, and a part of the heater cannot be cooled. Pulsation can therefore be used to cool a larger area using the same average mass flow rate.

For $\mathrm{L} / \mathrm{d}_{\mathrm{N}}=33$ the enhancement factors within $\mathrm{Re}=41,700$ remain as for $\mathrm{L} / \mathrm{d}_{\mathrm{N}}=3$, but reduce to a maximum of $5 \%(20 \%$ for $\mathrm{L} / \mathrm{d}_{\mathrm{N}}=3$ ) compared to $\mathrm{Re}=31000$. As mentioned above, this is caused by the increase of the splattered mass fraction, $\xi$, with increasing $L / d_{N}(\xi=0,0.35,0.44(0,0.15,0.4)$ for $\mathrm{L} / \mathrm{d}_{\mathrm{N}}=3,33,167$ and $\operatorname{Re}=41700(\operatorname{Re}=31000)$ for continuous jet impingement [11]). For the highest nozzle distance $\mathrm{L} / \mathrm{d}_{\mathrm{N}}=167$ the influence of pulsation is reduced. A possible reason is the growth of the jet front with growing nozzle distances (Fig. 10), which seems to exhibit a higher splattered mass fraction than the continuous part of the jet section. This would reduce the heat transfer for a certain amount of time after the jet section impinges, which would especially reduce the overall heat transfer of shorter pulses (high frequency and low duty cycle) and thereby explain the observed decrease.

The influence of the splattered mass fraction becomes dominant for the cases summarized in Fig. 11. In this diagram, the average Stanton numbers for continuous and pulsating jet impingement experiments, characterized by the same average mass flow rate $(\mathrm{Re}=31000, \mathrm{DC}=100$ and $\mathrm{Re}=59000$, $\mathrm{DC}=50$ ), are compared with each other. If the mass flow rate stays identical, the pulsation leads to a reduction of the heat transfer efficiency for $\mathrm{L} / \mathrm{d}_{\mathrm{N}} \geq 33$ due to a drastic increase of the splattered mass fraction with an increase of the nozzle distance a)

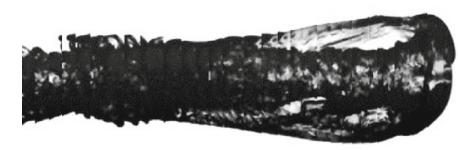

..

b)

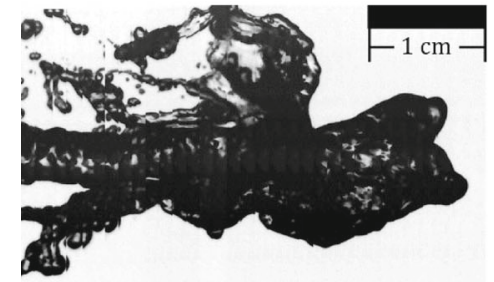

c)

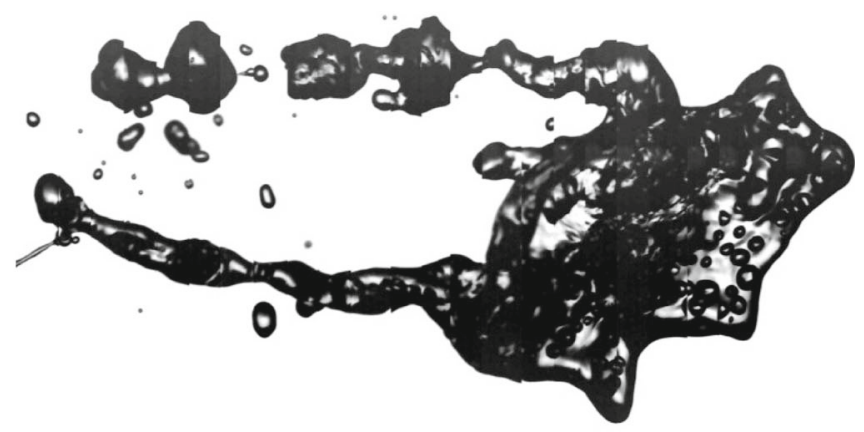

Fig. 10 Stitched images (procedure described in [11]) reconstructing the jet front for $\mathrm{Re}=41,700$, which increases in size with increasing nozzle distance $\mathrm{L} / \mathrm{d}_{\mathrm{N}}=3,33$ and $167(\mathbf{a}, \mathbf{b}$ and $\mathbf{c})$ 
Fig. 11 Mean Stanton number for $\mathrm{Re}=59,600$ as well as further Reynolds numbers, for different pulsation frequencies $(\mathrm{Hz})$ and duty cycles $(\%)$. $\left(\mathrm{L} / \mathrm{d}_{\mathrm{N}}=3,33\right.$ and 67)

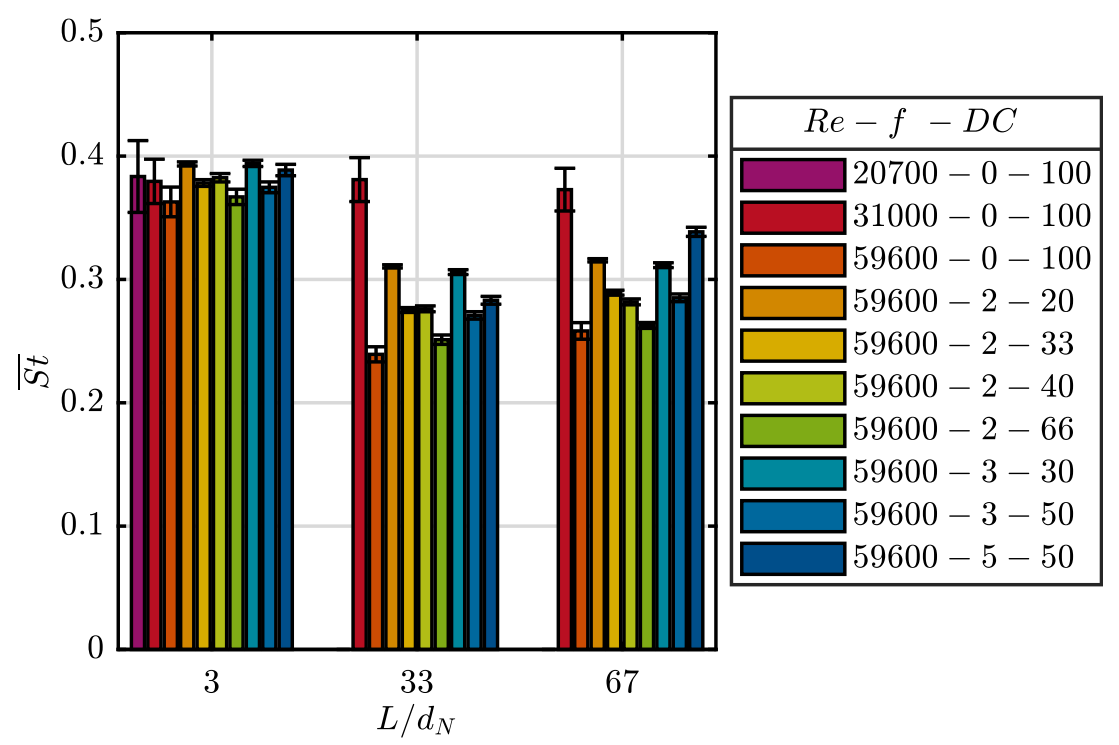

for $\mathrm{Re}=59000\left(\xi=0,0.5,0.48\right.$ for $\mathrm{L} / \mathrm{d}_{\mathrm{N}}=3,33,67$, respectively). Additionally, it can be seen that the influence of pulsation is comparably low for the lowest nozzle distance. First, the heat transfer during jet impingement is higher than at lower Reynolds numbers and/or higher nozzle distances. Second, as can be observed in Fig. 7b, the wall flow spreads out far beyond the border of the heater. For higher nozzle distances (a higher rate of splattering) or lower Reynolds numbers, the extent of the RFZ reduces considerably (compare, [11, 24]).

Assume that the mass of water accumulated in the rope is approximately similar for all cases. Then, the larger the RFZ, the lower is the share of the mass accumulated within the rope, which flows over the heater and cools it during phase (iii). The described influence is illustrated in Fig. 12, where the red lines span an angle of either $60^{\circ}$ $\left(\mathrm{L} / \mathrm{d}_{\mathrm{N}}=3\right.$, left $)$, or $71^{\circ}\left(\mathrm{L} / \mathrm{d}_{\mathrm{N}}=33\right.$, right $)$. Both effects, the higher heat transfer rate during jet impingement and the smaller amount of water located above the heater, in relation to the impinged mass during one pulse, decrease the relative contribution of the draining wave to the overall heat transfer and thus reduce the effect imposed by pulsation.

Finally, and also related to the ratio of the sizes of the heater and the RFZ, it can be seen that for $\mathrm{Re}=20700$ a pulsation at the frequency of $1 \mathrm{~Hz}$ increases the heat transfer efficiency (see Fig. 9). For other Reynolds numbers, this was not the case due to the relatively long pause time of about $350 \mathrm{~ms}$ between the draining wave has passed the POI and the jet impingement of the next pulse, in which only little cooling is provided. However, for this setting the heat transfer efficiency is increased, which is due to a dewetting phenomenon, which will be addressed in the following section.
Fig. 12 Illustration of water above the heater for $\operatorname{Re}=59,600$ and $\mathrm{L} / \mathrm{d}_{\mathrm{N}}=3$ (left) and 33 (right)

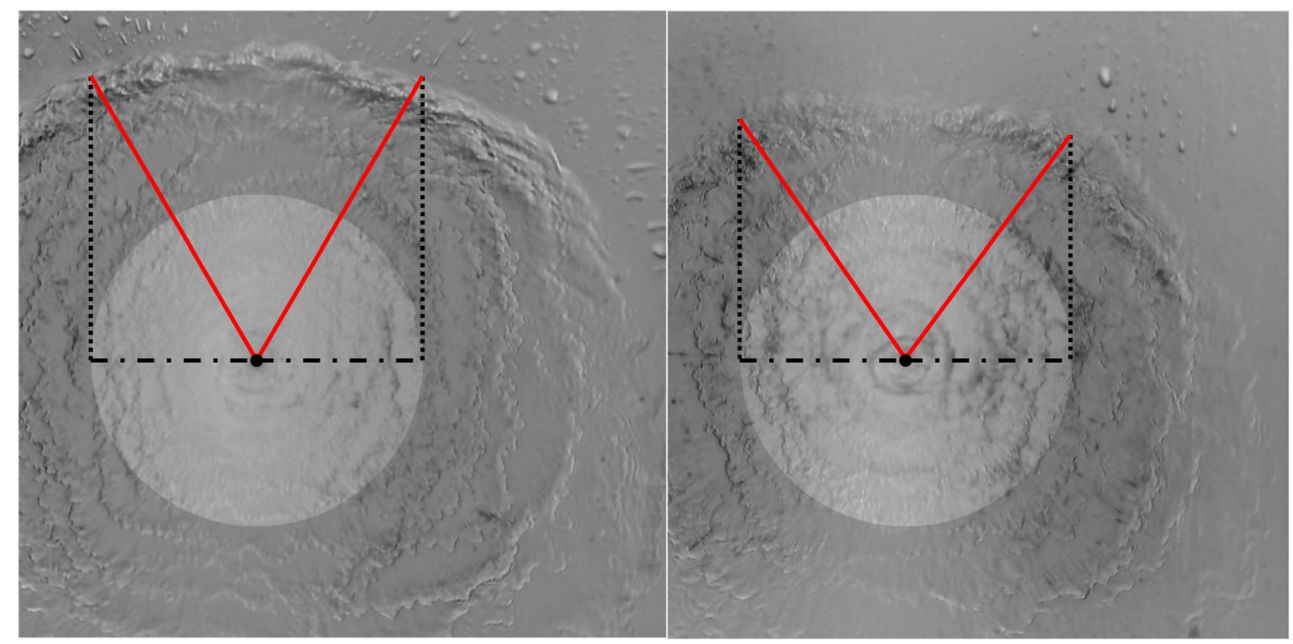


Fig. 13 Instability in the rope flow above the POI (a). Wall temperature for continuous ( $\mathrm{f}=0$, $\mathrm{DC}=100 \%, \square)$ and pulsating jet impingement $(\mathrm{f}=1 \mathrm{~Hz}, \mathrm{DC}=$ $50 \%$, o) for selected thermocouple positions above the POI (b). $\left(\mathrm{Re}=20700\right.$ and $\mathrm{L} / \mathrm{d}_{\mathrm{N}}=$ 3 )

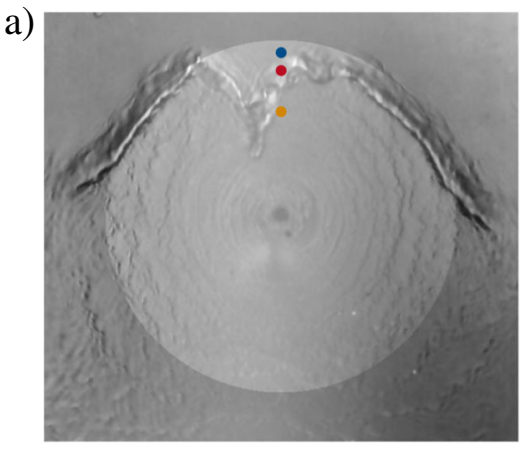

\subsection{Pulsation and dewetting}

In the case of impingement of smooth jets at low nozzle distances the rope above the POI can grow to a thickness which gives rise to the Rayleigh-Taylor instability leading to dripping of the liquid. During the thickening process, the weight of the rope flow increases, and thus, its distance from the POI reduces, since its weight has to be balanced by the wall-flow momentum, which was described at the beginning of section 3 (see also Fig. 3a and supplementary mat. 1). The consequence of the instability is illustrated in Fig. 13a for $\mathrm{Re}=20700$ and a nozzle distance $L / d_{N}=3$. During the experiment on the heater, it was visible that such an instability can lead to partial dewetting of the heater down to the region of the thermocouple at $56 \mathrm{~mm}$ above POI. Since the formed bulge suppresses the fresh water supply to regions above, the wall temperature increases. Thus, the temperature of the thin film above the bulge increases quickly, resulting in a strong temperature gradient along the radial coordinate, which can induce a Marangoni flow. This eventually leads to persisting dewetting of the heater and causes the temperature increase shown in Fig. 13b. The mean temperatures for the thermocouples at $40 \mathrm{~mm}(56 \mathrm{~mm})$ exhibit $5.8 \mathrm{~K}$ $(10.9 \mathrm{~K})$ for continuous flow. For pulsation, the mean temperatures exhibit $12 \mathrm{~K}(17.8 \mathrm{~K})$ for pulsation at the corresponding thermocouples, which inherits a factor near 0.5 and close to the duty cycle. However, it is seen at $63 \mathrm{~mm}$ above the POI that the wall temperature increases from $12 \mathrm{~K}$ to $18.2 \mathrm{~K}$ reaching almost $90 \%$ of the value $(20.3 \mathrm{~K})$ achieved with half the average mass flow rate over a time span of $15 \mathrm{~s}$. For comparison, the time span between the build-up of the bulge and dripping amounts to $100-300 \mathrm{~ms}$ on the Plexiglas ${ }^{\circledR}$. For pulsating jet impingement, the momentum of the spreading wall flow rewets the upper part of the heater in 29 of 30 cycles, and thus the entire heater is cooled. This example shows the power of pulsation to wet dry or to rewet dewetted regions. Therefore, using pulsating jet impingement could be beneficial in other related subjects, where dry patches can occur in the draining film below the POI, such as tank cleaning [10,22], or in the cylindrical baffle of a feedwater deaerator [12].

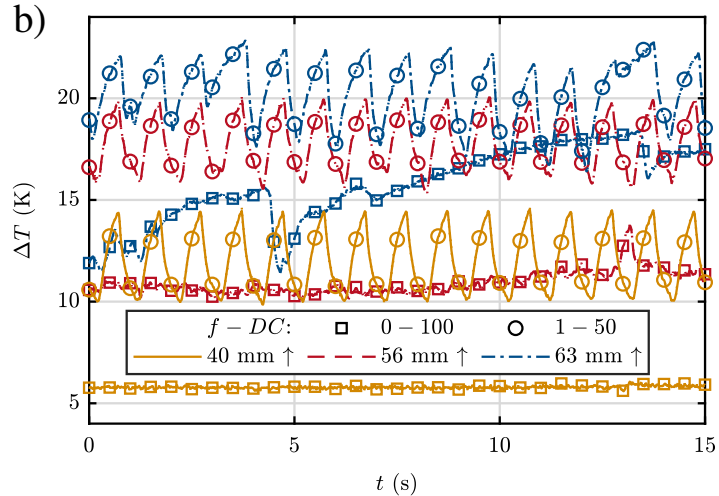

\section{Conclusions}

In this work, pulsating water jets impinging horizontally on a vertical wall have been investigated regarding their heat transfer efficiency and evaluated using the Stanton number. Pulsation in the investigated frequency regime induces complex wall-flow patterns, which can be subdivided into three phases. The spreading phase (i), a quasi-steady phase (ii), which only exists, if the jet is turned on sufficiently long, and the draining phase (iii). The latter phase is dominated by a wave, which is formed from the rope created in phases (i) and (ii). Increases in heat transfer efficiency for pulsating jets can be mainly assigned to the contribution of this draining wave to heat transfer. As the wave drains its temperature increases, and thereby its ability to cool decreases. Thus, the contribution of phase (iii) to heat transfer is constricted to the upper part of the heater. If the pause time is insufficiently long, the draining wave does not pass the POI during phase (iii) before the next pulse impinges. Then the spreading of the wall flow can be significantly decelerated, by a collision with the draining wave, which can reduce heat transfer during phase (i). However, the efficiency generally increases with increasing frequency and decreasing duty cycle.

Two cases have been distinguished in order to evaluate heat transfer efficiency:

First, a comparison within a set of parameters with equal Reynolds number [Eq. (3)], but different pulsation frequencies and duty cycles. The equal Reynolds number implies a comparable wetted area. In this case it was shown that the heat transfer efficiency can be increased up to $26 \%$ using pulsation, while the heat transport itself is - due to the reduced amount of cooling liquid - weakened. In addition, pulsation showed to be able to wet areas that were dewetted during continuous jet impingement.

Second, a constant mass flow rate. In the investigated regime of $R e=20700-59000$, the splattered mass fraction is extremely depending on the Reynolds number for $\mathrm{L} / \mathrm{d}_{\mathrm{N}} \geq 17$ $[8,11]$. When comparing a pulsating jet with a continuous jet with the same mass flow rate, the Reynolds number - defined 
by the pulsation duty cycle - is higher, and the heat transferred to the draining wave is overcome by the generally lower heat transfer rate, due to increased splattering. In such cases, a reduction in efficiency was notified. Therefore, the use of pulsation should be constricted to low nozzle distances. Then, heat transfer efficiency could be increased by up to $12 \%$. But pulsation can also be used to increase the cooling area with a set mass flow rate. In order to gain a deeper understanding of the underlying processes, the investigation of the hydrodynamics is necessary. Measuring the influence of pulsation on splattering as well as film thickness measurement - especially in the hydraulic-jump region - are part of ongoing work. It was also shown that pulsation could be more promising for smaller Reynolds numbers, in combination with smaller cooling areas.

Funding Open Access funding enabled and organized by Projekt DEAL.

Open Access This article is licensed under a Creative Commons Attribution 4.0 International License, which permits use, sharing, adaptation, distribution and reproduction in any medium or format, as long as you give appropriate credit to the original author(s) and the source, provide a link to the Creative Commons licence, and indicate if changes were made. The images or other third party material in this article are included in the article's Creative Commons licence, unless indicated otherwise in a credit line to the material. If material is not included in the article's Creative Commons licence and your intended use is not permitted by statutory regulation or exceeds the permitted use, you will need to obtain permission directly from the copyright holder. To view a copy of this licence, visit http://creativecommons.org/licenses/by/4.0/.

\section{References}

1. Stevens J, Webb BW (1991) Local heat transfer coefficients under an axisymmetric, Singlephase liquid jet. J Heat Transf 113:71-77

2. Liu X, Lienhard JH (1989) Liquid jet impingement heat transfer on a uniform flux surface. Heat Transfer Phenomena in Radiation, Combustion and Fires 106: 523-530

3. Liu X, Lienhard JH, Lombara JS (1991) Convective heat transfer by impingement of circular liquid jets. J Heat Transf 113:571-582

4. Zumbrunnen DA, Incropera FP, Viskanta R (1989) Convective heat transfer distributions on a plate cooled by planar water jets. $\mathrm{J}$ Heat Transf 111:889-896

5. Stevens J, Webb BW (1992) Measurement of the free surface flow structure under an impinging, free liquid jet. J Heat Transf 114:7984

6. Lienhard JH, Liu X, Gabour LA (1992) Splattering and heat transfer during Impingment of a turbulent jet. J Heat Transf 114:362372

7. Zhan Y, Oya N, Enoki K et al (2018) Droplet generation during liquid jet impingement onto a horizontal plate. Exp Thermal Fluid
Sci 98:86-94. https://doi.org/10.1016/j.expthermflusci.2018.05. 022

8. Bhunia SK, Lienhard JH (1994) Surface disturbance evolution and the splattering of turbulent liquid jets. J Fluids Eng 116:721-727

9. Bhunia SK, Lienhard JH (1994) Splattering During Tubulent Liquid Jet Impingement on Solid Targets. J Fluid Mech 116:338344

10. Wang T, Faria D, Stevens LJ et al (2013) Flow patterns and draining films created by horizontal and inclined coherent water jets impinging on vertical walls. Chem Eng Sci 102:585-601. https://doi.org/10.1016/j.ces.2013.08.054

11. Wassenberg JR, Stephan P, Gambaryan-Roisman T (2019) The influence of splattering on the development of the wall film after horizontal jet impingement onto a vertical wall. Exp Fluids 60:429. https://doi.org/10.1007/s00348-019-2810-6

12. Kim H, Choi H, Kim D et al (2020) Experimental study on splash phenomena of liquid jet impinging on a vertical wall. Exp Thermal Fluid Sci 116:110111. https://doi.org/10.1016/j.expthermflusci. 2020.110111

13. Gabour LA, Lienhard JH (1994) Wall roughness effects on stagnation-point heat transfer Beaneath an impinging liquid jet. J Heat Transf 116:81-87

14. Zumbrunnen DA, Balasubramanian M (1995) Convective heat transfer enhancement due to gas injection into an impinging liquid jet. J Heat Transf 117:1011. https://doi.org/10.1115/1.2836275

15. Zumbrunnen DA, Aziz M (1993) Convective heat transfer enhancement due to intermittency in an impinging jet. J Heat Transf 115: 91-98. https://doi.org/10.1115/1.2910675

16. Zumbrunnen DA (1992) Transient convective heat transfer in planar stagnation flows with time-varying surface heat flux and temperature. J Heat Transf 114:85. https://doi.org/10.1115/1.2911272

17. Mladin EC, Zumbrunnen DA (1995) Dependence of heat transfer to a pulsating stagnation flow on pulse characteristics. J Thermophys Heat Transf 9:181-192. https://doi.org/10.2514/3.645

18. Sheriff HS, Zumbrunnen DA (1994) Effect of flow pulsations on the cooling effectiveness of an impinging jet. J Heat Transf 116: 886. https://doi.org/10.1115/1.2911463

19. Lewis SR, Anumolu L, Trujillo MF (2013) Numerical simulations of droplet train and free surface jet impingement. Int J Heat Fluid Flow 44:610-623. https://doi.org/10.1016/j.ijheatfluidflow.2013. 09.001

20. Middelberg G, Herwig H (2009) Convective heat transfer under unsteady impinging jets: the effect of the shape of the unsteadiness. Heat Mass Transf 45:1519-1532. https://doi.org/10.1007/s00231009-0527-4

21. Bhagat RK, Wilson DI (2016) Flow in the thin film created by a coherent turbulent water jet impinging on a vertical wall. Chem Eng Sci 152:606-623. https://doi.org/10.1016/j.ces.2016.06.011

22. Wilson DI, Le BL, Dao HDA et al (2012) Surface flow and drainage films created by horizontal impinging liquid jets. Chem Eng Sci 68:449-460. https://doi.org/10.1016/j.ces.2011.10.003

23. Bhagat RK, Jha NK, Linden PF et al (2018) On the origin of the circular hydraulic jump in a thin liquid film. J Fluid Mech 851:11. https://doi.org/10.1017/jfm.2018.558

24. Chee MWL, Ahuja TV, Bhagat RK et al (2019) Impinging jet cleaning of tank walls: effect of jet length, wall curvature and related phenomena. Food Bioprod Process 113:142-153. https://doi. org/10.1016/j.fbp.2018.10.005

Publisher's note Springer Nature remains neutral with regard to jurisdictional claims in published maps and institutional affiliations. 